OPEN ACCESS

Edited by:

Ignacio Mata,

Cleveland Clinic, United States

Reviewed by:

Oriol Dols-Icardo,

Sant Pau Institute for Biomedical

Research, Spain

Jordi Clarimon,

Sant Pau Institute for Biomedical

Research, Spain

*Correspondence:

Lasse Pihlstrøm

lasse.pihlstrom@medisin.uio.no

Specialty section:

This article was submitted to

Neurogenetics,

a section of the journal

Frontiers in Neurology

Received: 19 November 2020

Accepted: 11 January 2021

Published: 05 February 2021

Citation:

Tunold J-A, Geut H, Rozemuller JMA, Henriksen SP, Toft M, van de

Berg WDJ and Pihlstrom L (2021)

APOE and MAPT Are Associated With

Dementia in Neuropathologically

Confirmed Parkinson's Disease.

Front. Neurol. 12:631145

doi: 10.3389/fneur.2021.631145

\section{APOE and MAPT Are Associated With Dementia in Neuropathologically Confirmed Parkinson's Disease}

\author{
Jon-Anders Tunold ${ }^{1,2}$, Hanneke Geut ${ }^{3}$, J. M. Annemieke Rozemuller ${ }^{4}$, \\ Sandra Pilar Henriksen ${ }^{1}$, Mathias Toft ${ }^{1,2}$, Wilma D. J. van de Berg ${ }^{3}$ and Lasse Pihlstrøm ${ }^{1 *}$ \\ ${ }^{1}$ Department of Neurology, Oslo University Hospital, Oslo, Norway, ${ }^{2}$ Institute of Clinical Medicine, University of Oslo, Oslo, \\ Norway, ${ }^{3}$ Section Clinical Neuroanatomy and Biobanking, Department of Anatomy and Neurosciences, Amsterdam UMC, \\ Location Vrije Universiteit Amsterdam, Amsterdam Neuroscience, Amsterdam, Netherlands, ${ }^{4}$ Department of Pathology, \\ Amsterdam UMC, Location Vrije Universiteit Amsterdam, Amsterdam Neuroscience, Amsterdam, Netherlands
}

Introduction: Cognitive decline and dementia are common and debilitating non-motor phenotypic features of Parkinson's disease with a variable severity and time of onset. Common genetic variation of the Apolipoprotein $\mathrm{E}(A P O E)$ and micro-tubule associated protein tau (MAPT) loci have been linked to cognitive decline and dementia in Parkinson's disease, although studies have yielded mixed results. To further elucidate the influence of APOE and MAPT variability on dementia in Parkinson's disease, we genotyped postmortem brain tissue samples of clinically and pathologically well-characterized Parkinson's donors and performed a survival analysis of time to dementia.

Methods: We included a total of 152 neuropathologically confirmed Parkinson's disease donors with or without clinical dementia during life. We genotyped known risk variants tagging the APOE \&4 allele and MAPT $\mathrm{H} 1 / \mathrm{H} 2$ inversion haplotype. Cox proportional hazards regression analyses adjusted for age at onset, sex and genetic principal components were performed to assess the association between the genetic variants and time from motor onset to onset of dementia.

Results: We found that both the APOE $\varepsilon 4$ allele (HR 1.82, $95 \% \mathrm{Cl} 1.16-2.83, p=0.009)$ and MAPT H1-haplotype (HR 1.71, $95 \% \mathrm{Cl} 1.06-2.78, p=0.03$ ) were associated with earlier development of dementia in patients with Parkinson's disease.

Conclusion: Our results provide further support for the importance of APOE $\varepsilon 4$ and MAPT H1-haplotype in the etiology of Parkinson's disease dementia, with potential future relevance for risk stratification and patient selection for clinical trials of therapies targeting cognitive decline in Parkinson's disease.

Keywords: parkinson's disease, dementia, neuropathology, genetics, association study, APOE, MAPT

\section{INTRODUCTION}

Parkinson's disease (PD) is a heterogenous disorder in terms of clinical presentation and rate of progression. Dementia is one of the most debilitating non-motor manifestations of the disease, with broad implications for both patients and caregivers (1-3). Longitudinal studies have shown that most patients ultimately develop Parkinson's disease dementia (PDD) if they survive long 
enough, although the time of onset is highly variable $(4,5)$. Cognitive disability is not only a feature of advanced disease, as $36 \%$ of patients meet criteria for mild cognitive impairment already at clinical diagnosis (6) and $17 \%$ of patients develop dementia within five years from disease onset (7). Identification of biomarkers, including common genetic variants predicting early cognitive decline and dementia, could provide important insights into the biological and molecular underpinnings of PDD, benefit recruitment to clinical trials and identify potential targets for novel therapeutics.

Genome-wide association studies (GWAS) have identified genetic susceptibility loci for sporadic PD, with the latest metaanalysis bringing the number up to 90 risk signals across 78 loci (8). Genetic variability may not only affect the risk of developing PD, but also influence the clinical course of the disease. Several genetic loci have been hypothesized as risk factors for dementia in sporadic PD, among them APOE and MAPT, showing partly conflicting results in previously published reports (9).

Coding variation in $A P O E$ on chromosome 19 gives rise to three common alleles: $\varepsilon 2, \varepsilon 3$, and $\varepsilon 4$. The APOE $\varepsilon 4$ allele is a strong and well-established genetic risk factor for Alzheimer's disease (AD) (10), and the top GWAS signal in dementia with Lewy bodies (DLB) (11). While APOE does not seem to alter the risk for PD in itself according to GWAS results, the $\varepsilon 4$ allele has been studied as a potential risk factor for cognitive decline and development of dementia in PD patients, with several larger studies reporting a significant association $(12,13)$.

An inversion polymorphism on chromosome $17 \mathrm{q} 21$, containing MAPT and several other genes, gives rise to the $\mathrm{H} 1$ and H2 haplotypes in European populations (14). Singlenucleotide polymorphisms (SNPs) tagging the H1-haplotype have consistently been among the most significant association signals in GWAS of PD-risk $(8,15,16)$. The MAPT gene encodes the tau protein that is found to aggregate in neurofibrillary tangles (NFT), a core neuropathological feature of AD, but also found in varying degrees in PD and PDD patients upon autopsy $(17,18)$. Interestingly, the MAPT H1-haplotype has also been reported to be associated with an accelerated rate of cognitive decline and earlier development of dementia in PD patients $(7,19,20)$, yet larger studies have not been able to replicate this finding $(12,21)$.

Discrepant results across previous genetic association studies of cognitive outcomes in PD could potentially arise from differences in methodology, in particular with respect to inclusion criteria, duration of follow-up and outcome measures used to assess cognitive decline. A study based on brain bank samples can take advantage of gold standard diagnostics and clinical data that cover the patients' entire lifespan. In this study, we investigated the association of SNPs in the APOE and MAPT loci with time to dementia by retrospective survival analysis in neuropathologically defined PD brain donors.

\section{METHODS}

\section{Subjects}

All subjects were neuropathologically confirmed patients with PD or PDD from the Netherlands Brain Bank (NBB, www.brainbank.nl). All brains available from the NBB from 1989 to 2017 ( $n=3,853$ ) were considered for study inclusion according to the selection criteria. Written, informed consent for the use of clinical information and tissue samples for research purpose, was collected from the donors or their next of kin.

Standardized brain autopsies and neuropathological examinations were performed by experienced neuropathologists (AR and WB). Neuropathological assessment of Lewy Body (LB)-related $\alpha$-synuclein pathology was done according to BrainNet Europe guidelines (22) and assessment of $\mathrm{AD}$ neuropathologic change was done according to National Institute on Aging-Alzheimer's Association (NIA-AA) guidelines (23).

Clinical information was extracted from the medical records provided by the NBB. The diagnosis of PD was based on the combination of the clinical syndrome of PD [UK Parkinson's Disease Society Brain Bank criteria (24)], and moderate to severe loss of neurons in the substantia nigra in association with Lewy pathology in at least the brainstem with or without limbic and cortical brain regions (25). When dementia had been diagnosed during life, donors fulfilling these criteria were classified as PDD. A diagnosis of dementia was made during life by a neurologist or geriatrician, or retrospectively based on neuropsychological test results showing disturbances in at least two core cognitive domains (26) or Mini-Mental State Examination (MMSE) score $<20$. Distinction between DLB and PDD was made based on the 1 -year rule, where dementia presenting before or within 1 year of parkinsonism onset was diagnosed as DLB, and not included in this study (27). Cases diagnosed as having both PD and AD were also excluded from the study.

\section{Genotyping}

DNA was extracted from brain tissue. Genotyping was carried out on the Infinium ${ }^{\circledR}$ NeuroChip Consortium Array (Illumina, San Diego, CA USA) (28). Quality control was carried out in PLINK version 1.9 (29). Samples passing standard quality control, including filtering of variants and individuals based on call rate $(<0.95)$, Hardy-Weinberg equillibrium $(p<0.000001)$, relatedness (pi-hat $>0.125$ ), excess heterozygosity ( $>4 \mathrm{SD}$ from mean), sex-check and ancestry assessed by principal component plots, were imputed using the Michigan Imputation Server (30). We selected rs1800547 to discriminate between the MAPT H1 and $\mathrm{H} 2$ haplotypes, and used rs429358 and rs7412 to define the $A P O E \varepsilon 2, \varepsilon 3$, and $\varepsilon 4$ alleles as previously described $(31,32)$.

The NeuroChip array was also used to screen for known pathogenic mutations in relevant Mendelian PD genes. Covering the majority of definitely and probably pathogenic variants in the autosomal dominant genes SNCA, LRRK2, and VPS35, we identified no mutation carriers (Supplementary Table 1).

\section{Statistical Analysis}

All statistical analyses were carried out in $\mathrm{R}$ (version 4.0.2; http://www.r-project.org). Differences in baseline demographics and clinical variables between patients with $\mathrm{PD}$ and PDD were assessed using $t$-tests for continuous variables and chi-square tests for categorical variables. Ordinal variables (neuropathological scores) were compared using the Wilcoxon Rank Sum Test, while associations between neuropathology 
TABLE 1 | Clinical characteristics of cases with Parkinson's disease non-demented (PDnD) and Parkinson's disease dementia (PDD).

\begin{tabular}{lccc}
\hline & PDnD & PDD & $\boldsymbol{p}$ \\
& $\mathbf{N = 7 1}$ & $\mathbf{N = 8 1}$ & \\
\hline Sex, male (\%) & $43(60.6)$ & $57(70.4)$ & 0.271 \\
Age at disease onset, mean (SD) & $61.3(13.0)$ & $64.2(9.5)$ & 0.117 \\
Age at dementia onset, mean (SD) & - & $73.7(7.0)$ & - \\
Disease duration, mean (SD) & $15.5(7.7)$ & $13.6(6.7)$ & 0.102 \\
Motor dementia interval, mean (SD) & - & $9.4(5.8)$ & - \\
Dementia duration, mean (SD) & - & $4.1(2.8)$ & - \\
Age at death, mean (SD) & $77.0(9.3)$ & $77.8(6.5)$ & 0.515 \\
\hline
\end{tabular}

SD: standard deviation. $P$ value from $t$-tests for continuous variables and chi-square tests for categorical variables (sex).

and genotypes were measured by odds ratios using ordinal logistic regression adjusting for age at death and sex. For the survival analysis we used the R package "survival." Cox proportional hazards regression models were employed to assess the relationship between genotype and dementia onset. The event variable was presence of dementia. As time variable we used disease duration at dementia onset for PDD and disease duration at death for PD. Separate analyses were carried out for each risk locus, with sex, age at motor symptom onset and the first five genetic principal components as covariates. We estimated hazard ratio (HR) and the $95 \%$ confidence interval (CI). P values for each covariate were obtained from the Wald test. The results were visualized as Cox regression-adjusted curves using the $\mathrm{R}$ package "survminer." A combined plotting and testing approach was employed to check the proportional hazards assumptions. A $p<0.05$ was used as significance threshold in this study.

\section{RESULTS}

One hundred sixty five donors ( $\operatorname{PD} n=79$ and $\operatorname{PDD} n=86$ ) were identified. A total of 13 cases were excluded for missing clinical, neuropathological or genotype data, or failing quality control. A total of 152 cases (PD $n=71$ and PDD $n=81$ ) meeting clinical and neuropathological criteria were included in the final analysis. The demographic and clinical characteristics are displayed in Table 1. There were no significant differences in sex distribution, age at disease onset, disease duration or age at death between PD and PDD patients.

Braak $\alpha$-synuclein stage $(p=0.01)$, Thal amyloid- $\beta(A \beta)$ phase $(p=0.001)$, Braak NFT stage $(p=0.003)$ and CERAD neuritic plaque score $(p<0.001)$ were all higher in PDD compared to PD patients (Figure 1 and Supplementary Table 2). Applying the NIA-AA criteria, intermediate or high AD co-pathology was present in 7\% (5 of 67) of PD patients and 14\% (11 of 80) of PDD patients. $A P O E \varepsilon 4$ was significantly associated with Thal $A \beta$ phase (OR 4.85, $p<0.001$ ) and CERAD neuritic plaque score (OR 4.97, $p<0.001)$, but not Braak NFT or Braak $\alpha$-synuclein stage
TABLE 2 | Risk variant frequencies and results from Cox proportional hazards regression models with age at onset, sex, and genetic principal components as covariates.

\begin{tabular}{|c|c|c|c|c|}
\hline Variant & Frequency & HR & $95 \% \mathrm{CI}$ for $\mathrm{HR}$ & $p$ \\
\hline \multirow[t]{2}{*}{ APOE $\varepsilon 4$} & PDnD: 0.11 & 1.82 & $1.16-2.83$ & 0.009 \\
\hline & PDD: 0.14 & & & \\
\hline \multirow[t]{2}{*}{ MAPT H1/H1 } & PDnD: 0.68 & 1.71 & $1.06-2.78$ & $0.03^{*}$ \\
\hline & PDD: 0.77 & & & \\
\hline
\end{tabular}

APOE, Apoliporotein E; HR, hazard ratio; Cl, confidence interval; MAPT, microtubuleassociated protein tau.

${ }^{*} P$ value from the Wald test.

(Supplementary Table 3). The MAPT H1-haplotype was not significantly associated with any of the neuropathological scores.

In the Cox proportional hazards model the $A P O E \& 4$ allele was significantly associated with a shorter time between $\mathrm{PD}$ onset and diagnosis of PDD (HR per $\varepsilon 4$ allele 1.82, $95 \%$ CI 1.162.83, $p=0.009$, Table 2 and Figure 2A). When Thal A $\beta$ phase or CERAD neuritic plaque score were added as covariates, the association with time to dementia was no longer significant ( $p$ $=0.23$ and $p=0.11$, respectively). The MAPT H1-haplotype was also significantly associated with a shorter time to dementia (HR per H1 haplotype $1.71,95 \%$ CI 1.06-2.78, $p=0.03$, Table 2 and Figure 2B). Later age at onset was significantly associated with shorter time to dementia in both models (HR 1.09, 95\% CI $1.06-1.12, p<0.001)$.

\section{DISCUSSION}

In this study we explored the genetic effects of MAPT and $A P O E$ on onset of dementia in PD in a neuropathologically characterized cohort. With the advantages of definite diagnosis and clinical data from the patients' entire lifespan, we found that even in a small sample, both the APOE $\varepsilon 4$ allele and the MAPT H1-haplotype were significantly associated with an accelerated onset of dementia in PD patients.

Several studies have examined the effects of $A P O E \varepsilon 4$ on cognitive decline and dementia in PD. Many of these have had cross-sectional design, and while some have demonstrated an association with APOE $\varepsilon 4$ and lower cognitive performance (21), others have failed to do so (33). Consistent with our results, a previous study of PD patients demonstrated earlier development of dementia among APOE \&4-carriers (HR 1.90, 95\% CI 1.053.44) (34). In line with our data, two recent meta-analyses reported an increased risk of dementia in PD patients who carried the $A P O E \& 4$ allele, although regional differences in effect size were noted $(35,36)$. Longitudinal studies have found associations with $A P O E \& 4$ and a more rapid cognitive decline measured on both screening instruments for global cognition $(37,38)$ and battery-style assessment of mental status $(12,39)$. In a recent GWAS on PD progression using longitudinal data from three large cohorts, the top hit for cognitive progression was rs429358 tagging $A P O E \& 4$ (40). In contrast, variants in the $A P O E$-gene were not associated with cognitive decline or dementia at 3.5, 5 , or 10 year follow-up in the CamPaIGN study, a UK incident cohort of PD patients $(7,20)$, or with shorter time to dementia 


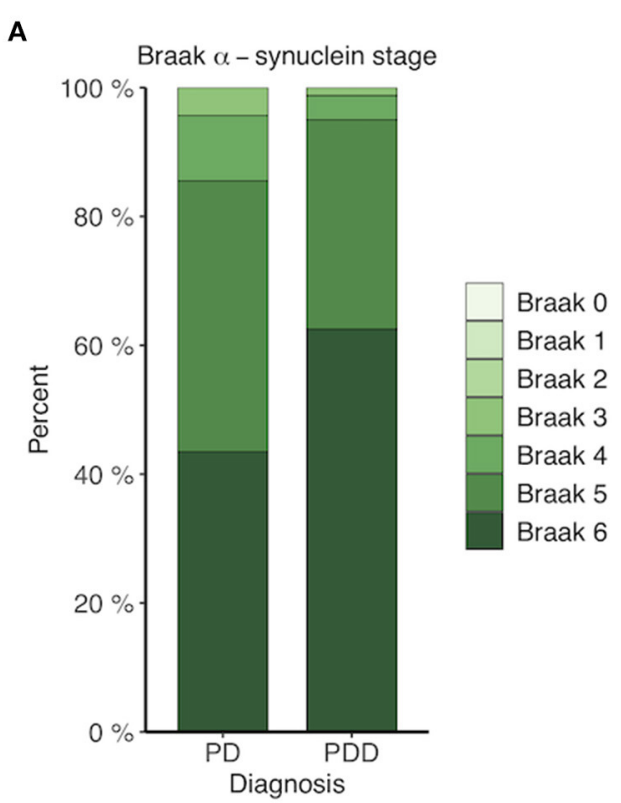

C

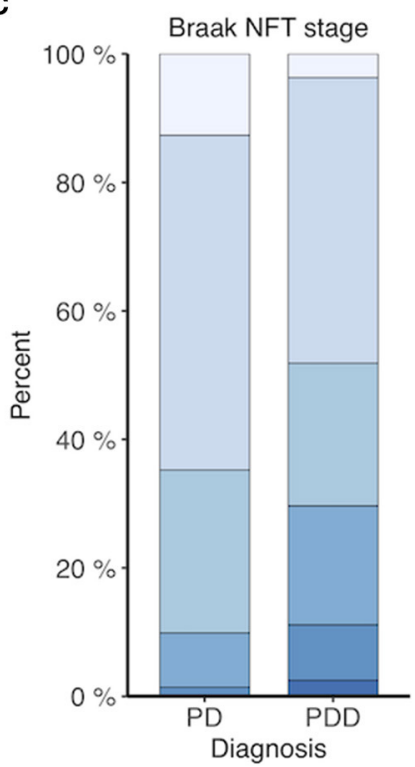

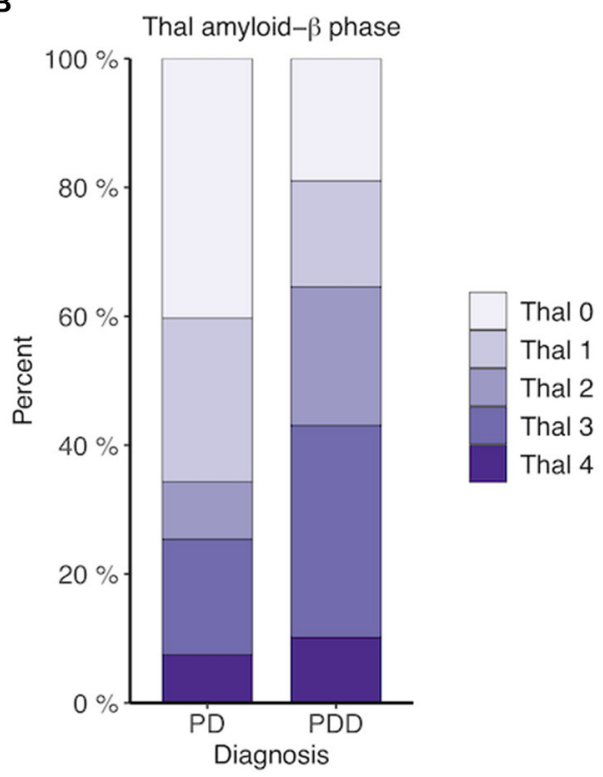

D

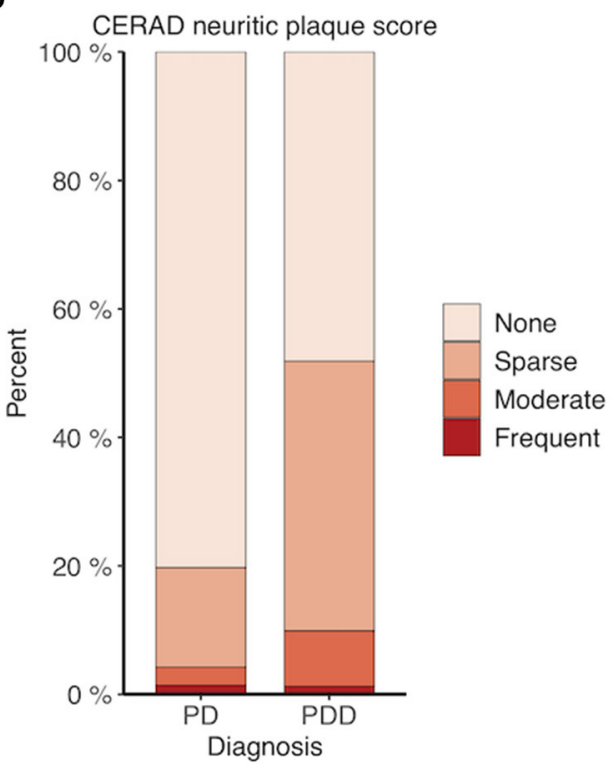

FIGURE 1 | Neuropathological scores for PD and PDD patients. (A) Braak $\alpha$-synuclein stage. (B) Thal amyloid- $\beta$ phase. (C) Braak neurofibrillary tangle (NFT) stage. (D) CERAD neuritic plaque score. PDD patients display more advanced LB, $A \beta$, and tau pathology compared to PD patients.

in another longitudinal study (41). While longitudinal designs represent a gold standard for tracking disease progression, they may be hampered by small sample size, short follow-up time and loss to follow-up. Taken together, the weight of evidence favors an effect of $A P O E$ on cognitive decline and dementia in $\mathrm{PD}$, further supported by our results.

We also found a significant association between MAPT H1 and time to dementia in PD. This locus is less established than $A P O E$ in the previous literature on genetic risk factors of cognitive progression. The CamPaIGN study was the first to report an association between the MAPT $\mathrm{H} 1 / \mathrm{H} 1$ genotype and cognitive decline in PD (19). The results were confirmed in the subsequent 5- and 10-year follow-up studies, supporting the MAPT H1/H1 genotype as predictive of dementia $(7,20)$. The association between MAPT genotype and PDD has later been replicated (42), while other studies have failed to do so 


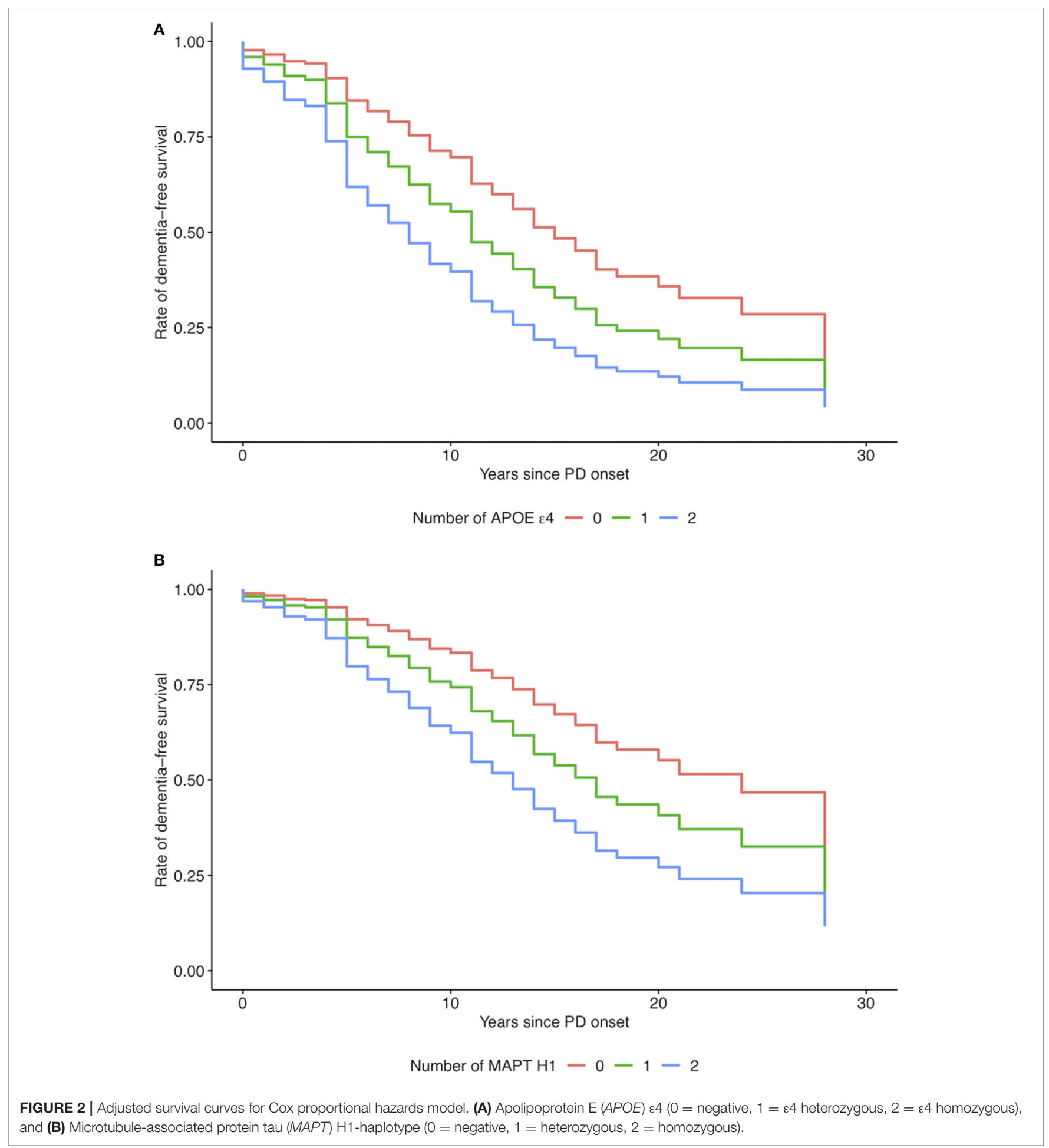

$(12,21,38)$. Contrary to our results, no association between MAPT $\mathrm{H} 1 / \mathrm{H} 1$ genotype and dementia onset was found in a previous survival analysis of $298 \mathrm{PD}$ patients where 59 progressed to dementia (34). A prospective investigation of 212 patients noted associations between MAPT $\mathrm{H} 1$ and specific cognitive outcome measures, but not with the overall rate of cognitive decline (12). The authors of this study hypothesized that the significant signal reported in the CamPaIGN study could represent an effect specific to early dementia development, as the CamPaIGN patients were included at diagnosis and assessed for progression to PDD at 3 years. Our data do not support this explanation of previously discrepant results, as the mean disease 
duration at dementia onset in the PDD group was 9-10 years in our study.

The underlying mechanisms linking $A P O E$ and MAPT variants to dementia are unclear, however neuropathological studies suggests that protein aggregation is pivotal in this association. In our study $A P O E \& 4$ was significantly associated with both Thal $\mathrm{A} \beta$ phases and CERAD neuritic plaque scores, supporting that $A P O E \& 4$ exerts its genetic risk on dementia primarily through $\mathrm{A} \beta$ neuropathology. The MAPT $\mathrm{H} 1$ haplotype was not associated with any neuropathological scores in our study. Concomitant $\mathrm{AD}$ pathology (A $\beta$ plaques and NFT) is found in variable amounts upon autopsy in PD and PDD brains, and is more prevalent in PDD compared to PD $(17,43,44)$. This is indeed true for our cases, as neuropathological examination revealed significantly more advanced Thal A $\beta$ phases, Braak NFT stages and CERAD neuritic plaque scores in PDD compared to PD samples.

Several lines of evidence support the role of cortical LB pathology as the major pathological driver of dementia in $\mathrm{PD}$ $(17,45)$, and in our study PDD donors had significantly more advanced Braak $\alpha$-synuclein stages than PD donors. While it seems likely that $A P O E \varepsilon 4$ mediates dementia through an $A \beta$ dependent pathway, previous studies have also reported an effect of $A P O E \& 4$ on cognitive outcome and severity of cortical LB pathology in patients with low concomitant AD-pathology $(46,47)$. Corroborating these findings, two recent experimental studies have shown evidence that APOE $\& 4$ may promote LB pathology independent of $A \beta$ pathology $(48,49)$. In our results, however, the association with dementia was dependent on $A \beta$, as the signal was no longer significant when adjusting for Thal $A \beta$ phase or CERAD neuritic plaque score.

While the presence of tau pathology has been correlated with reduced time to dementia (50), some evidence also supports that the MAPT H1-haplotype may influence the cortical LB burden (51), suggesting $M A P T$ also may promote dementia in more than one way. This idea was not supported by our data, but we note that the size of our study provided limited statistical power to disentangle potentially complex correlations between genotype and various neuropathologies. We also acknowledge that although the $\mathrm{H} 1$ inversion haplotype on chromosome 17 is commonly named after $M A P T$, it contains a number of other genes, and the mechanism driving the association signal for PD risk has yet to be unequivocally established. Recent evidence suggest that rather than MAPT, the disease-relevant gene could be the neighboring KANSL1, which is involved in autophagy regulation (52).

The clinical diagnosis of PD can be challenging, with a diagnostic accuracy of $80.6 \%$ when pathological examination is used as the gold standard (53). The strength of this study lies in the neuropathological confirmation of diagnosis and the retrospective overview of the clinical disease course from the patients' entire lifespan. Some limitations of our study should be noted. First, clinical information was obtained by retrospective review of medical records posing a risk for information bias, in particular regarding approximation of timing of events. However, the timing of motor symptom onset and dementia onset observed in this study harmonize well with previous reports $(17,54)$. Second, we acknowledge that lack of extensive neuropsychological evaluation is a limitation. In theory, death and dementia may be competing events and potentially bias the estimated effect of genotypes on dementia development. $A P O E \varepsilon 4$ has been associated with decreased longevity, but we observed similar age at death in PD and PDD, and any theoretical bias from this effect would skew results in the opposite direction of our findings (55). Further corroboration of the genetic associations reported here is warranted, preferably in longitudinal cohorts. Third, given the limited sample size and statistical power of our study, we narrowly selected only two candidate loci among several previously reported as associated with cognition in PD. A broader perspective on the genetic architecture of PDD would have to consider the contribution from loci such as SNCA, GBA, COMT and potentially others (9), and ideally also the possibility of synergistic interactions between these.

In conclusion, our study adds to the growing evidence supporting the role for not only APOE \&4 but also the MAPT $\mathrm{H} 1$ haplotype in development of dementia in PD. Detecting significant associations in a small, but wellcharacterized neuropathological sample, we anticipate that larger genetic association studies of neuropathological phenotypes will be a fruitful strategy to further disentangle molecular mechanisms in neurodegenerative disorders. Ultimately, a better understanding of genotype-phenotype correlations may facilitate precision medicine in $\mathrm{PD}$, improving risk prediction and patient stratification for novel targeted therapies.

\section{DATA AVAILABILITY STATEMENT}

The raw data supporting the conclusions of this article will be made available by the authors, without undue reservation.

\section{ETHICS STATEMENT}

The studies involving human participants were reviewed and approved by Regional Committees for Medical and Health Research Ethics, Norway. The patients/participants provided their written informed consent to participate in this study.

\section{AUTHOR CONTRIBUTIONS}

J-AT performed statistical analyses and drafted the manuscript. HG and JR contributed clinical and neuropathological data. $\mathrm{SH}$ contributed to genotyping. MT contributed to study design and organized the study. WB contributed clinical and neuropathological data, contributed to study design and organized the study. LP designed and organized the study and contributed to genotyping, data analyses and drafting of the manuscript. All authors took part in critical revision of the manuscript and approved the submitted version. 


\section{FUNDING}

This work was funded by grants from the South-Eastern Health Authority, Norway (2019065), the Norwegian Health Association (4999) and the Michael J. Fox Foundation (14227).

\section{ACKNOWLEDGMENTS}

The authors thank Michiel Kooreman for technical coordination of NBB brain tissue. In addition, we thank the autopsy team of Dept. Pathology, Amsterdam UMC, location VUmc for

\section{REFERENCES}

1. Winter Y, von Campenhausen S, Arend M, Longo K, Boetzel K, Eggert K, et al. Health-related quality of life and its determinants in Parkinson's disease: results of an Italian cohort study. Parkinsonism Relat Disord. (2011) 17:265-9. doi: 10.1016/j.parkreldis.2011.01.003

2. Vossius C, Larsen JP, Janvin C, Aarsland D. The economic impact of cognitive impairment in Parkinson's disease. Mov Disord. (2011) 26:1541-4. doi: $10.1002 / \mathrm{mds} .23661$

3. Fletcher P, Leake A, Marion MH. Patients with Parkinson's disease dementia stay in the hospital twice as long as those without dementia. Mov Disord. (2011) 26:919. doi: 10.1002/mds.23573

4. Hely MA, Reid WG, Adena MA, Halliday GM, Morris JG. The Sydney multicenter study of Parkinson's disease: the inevitability of dementia at 20 years. Mov Disord. (2008) 23:837-44. doi: 10.1002/mds.21956

5. Aarsland D, Andersen K, Larsen JP, Lolk A, Kragh-Sorensen P. Prevalence and characteristics of dementia in Parkinson disease: an 8-year prospective study. Arch Neurol. (2003) 60:387-92. doi: 10.1001/archneur.60.3.387

6. Foltynie T, Brayne CE, Robbins TW, Barker RA. The cognitive ability of an incident cohort of Parkinson's patients in the UK. The CamPaIGN study. Brain. (2004) 127:550-60. doi: 10.1093/brain/awh067

7. Williams-Gray CH, Evans JR, Goris A, Foltynie T, Ban M, Robbins TW, et al. The distinct cognitive syndromes of Parkinson's disease: 5 year follow-up of the CamPaIGN cohort. Brain. (2009) 132:2958-69. doi: 10.1093/brain/awp245

8. Nalls MA, Blauwendraat C, Vallerga CL, Heilbron K, Bandres-Ciga S, Chang $\mathrm{D}$, et al. Identification of novel risk loci, causal insights, and heritable risk for Parkinson's disease: a meta-analysis of genome-wide association studies. Lancet Neurol. (2019) 18:1091-102. doi: 10.1016/S1474-4422(19)30320-5

9. Fagan ES, Pihlstrom L. Genetic risk factors for cognitive decline in Parkinson's disease: a review of the literature. Eur J Neurol. (2017) 24:561-20. doi: 10.1111/ene.13258

10. Farrer LA, Cupples LA, Haines JL, Hyman B, Kukull WA, Mayeux $\mathrm{R}$, et al. Effects of age, sex, and ethnicity on the association between apolipoprotein E genotype and Alzheimer disease. A meta-analysis. APOE and Alzheimer Disease Meta Analysis Consortium. JAMA. (1997) 278:134956. doi: 10.1001/jama.278.16.1349

11. Guerreiro R, Ross OA, Kun-Rodrigues C, Hernandez DG, Orme T, Eicher JD, et al. Investigating the genetic architecture of dementia with Lewy bodies: a two-stage genome-wide association study. Lancet Neurol. (2018) 17:64-74. doi: 10.1016/S1474-4422(17)30400-3

12. Morley JF, Xie SX, Hurtig HI, Stern MB, Colcher A, Horn S, et al. Genetic influences on cognitive decline in Parkinson's disease. Mov Disord. (2012) 27:512-8. doi: $10.1002 / \mathrm{mds} .24946$

13. Pankratz N, Byder L, Halter C, Rudolph A, Shults CW, Conneally PM, et al. Presence of an APOE4 allele results in significantly earlier onset of Parkinson's disease and a higher risk with dementia. Mov Disord. (2006) 21:45-9. doi: 10.1002/mds.20663

14. Stefansson H, Helgason A, Thorleifsson G, Steinthorsdottir V, Masson G, Barnard J, et al. A common inversion under selection in Europeans. Nat Genet. (2005) 37:129-37. doi: 10.1038/ng1508 assistance with autopsies and Yvonne de Gier and Angela Ingrassia, Amsterdam UMC, location VUmc, for processing the tissue samples for genetic analysis. We also thank Chiara Cappelletti for assistance with DNA sample handling.

\section{SUPPLEMENTARY MATERIAL}

The Supplementary Material for this article can be found online at: https:/www.frontiersin.org/articles/10.3389/fneur. 2021.631145/full\#supplementary-material

15. Nalls MA, Pankratz N, Lill CM, Do CB, Hernandez DG, Saad M, et al. Largescale meta-analysis of genome-wide association data identifies six new risk loci for Parkinson's disease. Nat Genet. (2014) 46:989-93. doi: 10.1038/ng.3043

16. Simon-Sanchez J, Schulte C, Bras JM, Sharma M, Gibbs JR, Berg D, et al. Genome-wide association study reveals genetic risk underlying Parkinson's disease. Nat Genet. (2009) 41:1308-12. doi: 10.1038/ng.487

17. Irwin DJ, White MT, Toledo JB, Xie SX, Robinson JL, Van Deerlin V, et al. Neuropathologic substrates of Parkinson disease dementia. Ann Neurol. (2012) 72:587-98. doi: 10.1002/ana.23659

18. Geut H, Hepp DH, Foncke E, Berendse HW, Rozemuller JM, Huitinga I, et al. Neuropathological correlates of parkinsonian disorders in a large Dutch autopsy series. Acta Neuropathol Commun. (2020) 8:39. doi: 10.1186/s40478-020-00914-9

19. Goris A, Williams-Gray CH, Clark GR, Foltynie T, Lewis SJ, Brown J, et al. Tau and alpha-synuclein in susceptibility to, and dementia in, Parkinson's disease. Ann Neurol. (2007) 62:145-53. doi: 10.1002/ana.21192

20. Williams-Gray CH, Mason SL, Evans JR, Foltynie T, Brayne C, Robbins TW, et al. The CamPaIGN study of Parkinson's disease: 10-year outlook in an incident population-based cohort. J Neurol Neurosurg Psychiatry. (2013) 84:1258-64. doi: 10.1136/jnnp-2013-305277

21. Mata IF, Leverenz JB, Weintraub D, Trojanowski JQ, Hurtig HI, Van Deerlin VM, et al. APOE, MAPT, and SNCA genes and cognitive performance in Parkinson disease. JAMA Neurol. (2014) 71:1405-12. doi: 10.1001/jamaneurol.2014.1455

22. Alafuzoff I, Ince PG, Arzberger T, Al-Sarraj S, Bell J, Bodi I, et al Staging/typing of Lewy body related alpha-synuclein pathology: a study of the BrainNet Europe Consortium. Acta Neuropathol. (2009) 117:635-52. doi: 10.1007/s00401-009-0523-2

23. Montine TJ, Phelps CH, Beach TG, Bigio EH, Cairns NJ, Dickson DW, et al. National Institute on Aging-Alzheimer's Association guidelines for the neuropathologic assessment of Alzheimer's disease: a practical approach. Acta Neuropathol. (2012) 123:1-11. doi: 10.1007/s00401-011-0910-3

24. Hughes AJ, Daniel SE, Kilford L, Lees AJ. Accuracy of clinical diagnosis of idiopathic Parkinson's disease: a clinico-pathological study of 100 cases. $J$ Neurol Neurosurg Psychiatry. (1992) 55:181-4. doi: 10.1136/jnnp.55.3.181

25. Dickson DW, Braak H, Duda JE, Duyckaerts C, Gasser T, Halliday GM, et al. Neuropathological assessment of Parkinson's disease: refining the diagnostic criteria. Lancet Neurol. (2009) 8:1150-7. doi: 10.1016/S1474-4422(09)70238-8

26. Emre M, Aarsland D, Brown R, Burn DJ, Duyckaerts C, Mizuno Y, et al. Clinical diagnostic criteria for dementia associated with Parkinson's disease. Mov Disord. (2007) 22:1689-707; quiz 837. doi: 10.1002/mds.21507

27. McKeith IG, Boeve BF, Dickson DW, Halliday G, Taylor JP, Weintraub D, et al. Diagnosis and management of dementia with Lewy bodies: fourth consensus report of the DLB Consortium. Neurology. (2017) 89:88-100. doi: 10.1212/WNL.0000000000004058

28. Blauwendraat C, Faghri F, Pihlstrom L, Geiger JT, Elbaz A, Lesage $S$, et al. NeuroChip, an updated version of the NeuroX genotyping platform to rapidly screen for variants associated with neurological diseases. Neurobiol Aging. (2017) 57:247 e9-13. doi: 10.1016/j.neurobiolaging.2017. 05.009 
29. Chang CC, Chow CC, Tellier LC, Vattikuti S, Purcell SM, Lee JJ. Secondgeneration PLINK: rising to the challenge of larger and richer datasets. Gigascience. (2015) 4:7. doi: 10.1186/s13742-015-0047-8

30. Das S, Forer L, Schonherr S, Sidore C, Locke AE, Kwong A, et al. Nextgeneration genotype imputation service and methods. Nat Genet. (2016) 48:1284-7. doi: 10.1038/ng.3656

31. Mata IF, Yearout D, Alvarez V, Coto E, de Mena L, Ribacoba R, et al. Replication of MAPT and SNCA, but not PARK16-18, as susceptibility genes for Parkinson's disease. Mov Disord. (2011) 26:819-23. doi: $10.1002 / \mathrm{mds} .23642$

32. Williams-Gray CH, Goris A, Saiki M, Foltynie T, Compston DA, Sawcer SJ, et al. Apolipoprotein E genotype as a risk factor for susceptibility to and dementia in Parkinson's disease. J Neurol. (2009) 256:493-8. doi: 10.1007/s00415-009-0119-8

33. Federoff M, Jimenez-Rolando B, Nalls MA, Singleton AB. A large study reveals no association between APOE and Parkinson's disease. Neurobiol Dis. (2012) 46:389-92. doi: 10.1016/j.nbd.2012.02.002

34. Huertas I, Jesus S, Garcia-Gomez FJ, Lojo JA, Bernal-Bernal I, BonillaToribio $\mathrm{M}$, et al. Genetic factors influencing frontostriatal dysfunction and the development of dementia in Parkinson's disease. PLoS ONE. (2017) 12:e0175560. doi: 10.1371/journal.pone.0175560

35. Pang S, Li J, Zhang Y, Chen J. Meta-analysis of the relationship between the APOE gene and the onset of parkinson's disease dementia. Parkinsons Dis. (2018) 2018:9497147. doi: 10.1155/2018/9497147

36. Sun R, Yang S, Zheng B, Liu J, Ma X. Apolipoprotein E polymorphisms and parkinson disease with or without dementia: a meta-analysis including 6453 participants. J Geriatr Psychiatry Neurol. (2019) 32:3-15. doi: $10.1177 / 0891988718813675$

37. Schrag A, Siddiqui UF, Anastasiou Z, Weintraub D, Schott JM. Clinical variables and biomarkers in prediction of cognitive impairment in patients with newly diagnosed Parkinson's disease: a cohort study. Lancet Neurology. (2017) 16:66-75. doi: 10.1016/S1474-4422(16)30328-3

38. Paul KC, Rausch R, Creek MM, Sinsheimer JS, Bronstein JM, Bordelon Y, et al. APOE, MAPT, and COMT and parkinson's disease susceptibility and cognitive symptom progression. J Parkinsons Dis. (2016) 6:349-59. doi: $10.3233 / J P D-150762$

39. Tropea TF, Xie SX, Rick J, Chahine LM, Dahodwala N, Doshi J, et al. APOE, thought disorder, and SPARE-AD predict cognitive decline in established Parkinson's disease. Mov Disord. (2018) 33:289-97. doi: 10.1002/mds.27204

40. Tan MMX, Lawton MA, Jabbari E, Reynolds RH, Iwaki H, Blauwendraat C, et al. Genome-wide association studies of cognitive and motor progression in parkinson's disease. Mov Disord. (2020). doi: 10.1002/mds.28342

41. Phongpreecha T, Cholerton B, Mata IF, Zabetian CP, Poston KL, Aghaeepour $\mathrm{N}$, et al. Multivariate prediction of dementia in Parkinson's disease. NPJ Parkinsons Dis. (2020) 6:20. doi: 10.1038/s41531-020-00121-2

42. Seto-Salvia N, Clarimon J, Pagonabarraga J, Pascual-Sedano B, Campolongo A, Combarros O, et al. Dementia risk in Parkinson disease: disentangling the role of MAPT haplotypes. Arch Neurol. (2011) 68:359-64. doi: 10.1001/archneurol.2011.17

43. Compta Y, Parkkinen L, O'Sullivan SS, Vandrovcova J, Holton JL, Collins C, et al. Lewy- and Alzheimer-type pathologies in Parkinson's disease dementia: which is more important? Brain. (2011) 134:1493-505. doi: 10.1093/brain/awr031

44. Sabbagh MN, Adler CH, Lahti TJ, Connor DJ, Vedders L, Peterson LK, et al. Parkinson disease with dementia: comparing patients with and without Alzheimer pathology. Alzheimer Dis Assoc Disord. (2009) 23:295-7. doi: 10.1097/WAD.0b013e31819c5ef4
45. Kempster PA, O'Sullivan SS, Holton JL, Revesz T, Lees AJ. Relationships between age and late progression of Parkinson's disease: a clinico-pathological study. Brain. (2010) 133:1755-62. doi: 10.1093/brain/awq059

46. Tsuang D, Leverenz JB, Lopez OL, Hamilton RL, Bennett DA, Schneider JA, et al. APOE epsilon4 increases risk for dementia in pure synucleinopathies. JAMA Neurol. (2013) 70:223-8. doi: 10.1001/jamaneurol.2013.600

47. Dickson DW, Heckman MG, Murray ME, Soto AI, Walton RL, Diehl $\mathrm{NN}$, et al. APOE epsilon4 is associated with severity of Lewy body pathology independent of Alzheimer pathology. Neurology. (2018) 91:e118295. doi: 10.1212/WNL.0000000000006212

48. Zhao N, Attrebi ON, Ren Y, Qiao W, Sonustun B, Martens YA, et al. APOE4 exacerbates alpha-synuclein pathology and related toxicity independent of amyloid. Sci Transl Med. (2020) 12:eaay1809. doi: $10.1126 /$ scitranslmed.aay1809

49. Davis AA, Inman CE, Wargel ZM, Dube $U$, Freeberg BM, Galluppi A, et al. APOE genotype regulates pathology and disease progression in synucleinopathy. Sci Transl Med. (2020) 12:eaay3069. doi: $10.1126 /$ scitranslmed.aay3069

50. Irwin DJ, Grossman M, Weintraub D, Hurtig HI, Duda JE, Xie SX, et al. Neuropathological and genetic correlates of survival and dementia onset in synucleinopathies: a retrospective analysis. Lancet Neurol. (2017) 16:55-65. doi: 10.1016/S1474-4422(16)30291-5

51. Robakis D, Cortes E, Clark LN, Vonsattel JP, Virmani T, Alcalay RN, et al. The effect of MAPT haplotype on neocortical Lewy body pathology in Parkinson disease. J Neural Transm. (2016) 123:583-8. doi: 10.1007/s00702-016-1552-3

52. Soutar MPM, Melandri D, Annuario E, Welsh NJ, D'Sa K, Guelfi S, et al. Regulation of Mitophagy by the NSL Complex Underlies Genetic Risk for Parkinson's Disease at Chr16q11.2 and on the MAPT H1 Allele. BioRxiv (2020). Available online at: https://www.biorxiv.org/content/10.1101/2020.01. 06.896241v1.full (accessed December 27, 2020). doi: 10.1101/2020.01.06.8 96241

53. Rizzo G, Copetti M, Arcuti S, Martino D, Fontana A, Logroscino G. Accuracy of clinical diagnosis of Parkinson disease: a systematic review and meta-analysis. Neurology. (2016) 86:566-76. doi: 10.1212/WNL.0000000000 002350

54. Prokopenko I, Miyakawa G, Zheng B, Heikkinen J, Petrova Quayle D, Udeh-Momoh C, et al. Alzheimer's disease pathology explains association between dementia with Lewy bodies and APOE-epsilon4/TOMM40 long poly-T repeat allele variants. Alzheimers Dement. (2019) 5:814-24. doi: 10.1016/j.trci.2019.08.005

55. Blauwendraat C, Heilbron K, Vallerga CL, Bandres-Ciga S, von Coelln $\mathrm{R}$, Pihlstrom L, et al. Parkinson's disease age at onset genome-wide association study: defining heritability, genetic loci, and alphasynuclein mechanisms. Mov Disord. (2019) 34:866-75. doi: 10.1002/mds. 27659

Conflict of Interest: The authors declare that the research was conducted in the absence of any commercial or financial relationships that could be construed as a potential conflict of interest.

Copyright (C) 2021 Tunold, Geut, Rozemuller, Henriksen, Toft, van de Berg and Pihlstrøm. This is an open-access article distributed under the terms of the Creative Commons Attribution License (CC BY). The use, distribution or reproduction in other forums is permitted, provided the original author(s) and the copyright owner(s) are credited and that the original publication in this journal is cited, in accordance with accepted academic practice. No use, distribution or reproduction is permitted which does not comply with these terms. 